\title{
Oligopoly Power, Cross-Market Effects and Demand Relatedness: An Empirical Analysis
}

\author{
David V. Bouras \\ PhD, School of Business, Lincoln University, USA \\ Wesseh J. Wollo \\ PhD, Cooperative Research Programs/ \\ Department of Agriculture, Lincoln University, USA
}

\begin{abstract}
The goal of the paper is to develop a conceptual framework that can be used to examine market competitiveness and assess cross-market effects in a multi-product oligopoly consisting of firms producing and selling various demand-related products. The econometric model which consists of two inverse demand functions and two price-margin equations is applied to the US catfish processing industry. Focusing on fresh catfish filet and whole fresh catfish, the empirical results rule out the existence of cross-market effects, but give support to the existence of some degree of market power. In that setting, the oligopoly power indices are, respectively, $18.2 \%$ and $13.3 \%$ for fresh catfish filet and whole fresh catfish thereby indicating that the price distortion is more pronounced in the market for fresh catfish filet than it is in the market for whole fresh catfish.
\end{abstract}

Keywords: Oligopoly power, Cross-market Effects, Multi-product firms.

JEL Classification: C51, D24, D40

\section{Introduction}

The aim of this paper is to empirically evaluate the degree of market power and assess crossmarket effects in the US catfish processing industry. Towards this end, the paper uses and estimates a conjectural variation model that takes into account both the oligopoly power and cross-market effects.

The analysis of market power in the US catfish industry has been the focus of a large body of literature. For instance, Kinnucan and Sullivan (1986) applied Houck's method (1985) to analyze the degree of market power in the catfish industry in West Alabama. Using Appelbaum's model (1982), Kouka (1995) tested for market power and estimated the oligopoly power index in the US catfish processing industry. Bouras and Engle (2007) investigated the oligopoly and oligoposony power in the US catfish industry based on a statistic conjectural variation model. In a subsequent paper, Bouras et al., (2010) examined the oligopsony power in the US catfish industry using a dynamic conjectural variation model. Recently, Bouras et al., (2017b) used data from the US catfish industry to test the effectiveness of the New Empirical Industrial Organization (NEIO) technique in measuring the degree of 
market power. These papers relied, however, on the assumption that catfish processors produce and sell a single product. In reality, catfish processors produce and sell a variety of processed catfish products. These include, among others, fillet, shank fillet, nuggets, and steaks. As such the US catfish processing industry should be treated as a multi-product oligopoly predominantly producing and selling demand-related products. It is, therefore, important to take into consideration not only multimarket contacts but also cross-market effects when addressing the issue of market power in multi-product oligopolies.

The existing papers concerning the analysis of market power in multi-product oligopolies are scant. For example, Gelland and Spiller (1987), while focusing on the markets for credit denominated in the local currency and foreign currency, analyzed the degree of market power and the effect of barriers to entry on the degree of competitiveness in the Uruguayan banking sector. In another example, Schroeter and Azzam (1990) tested for both the oligopoly power and oligopsony power in the US meat industry with a special focus on the markets for beef and pork.

With a four-firm concentration ratio oscillating between $60 \%$ and $70 \%$ (Dillard, 1995), the US catfish processing industry is among the moderately concentrated industries in the United States. Such a concentrated structure has led economists and policy-makers to voice concerns about the exercise of market power by catfish processors. In that setting, previous empirical papers either supported or ruled out the existence of some degree of market power in the US catfish processing industry. For the intended analysis, we focus utterly on fresh catfish fillet and whole fresh catfish. These two processed products account for over $75 \%$ of total fresh catfish processed (USDA, 2012).

The remainder of this paper proceeds as follows: the next section presents the theoretical model and the empirical application; the third section contains data, the empirical estimation of the econometric models and statistical tests; the fourth section provides the estimation of the Lerner indices; the last section concludes the paper.

\section{Theoretical Model and Empirical Application}

\subsection{Theoretical Model}

The starting point of our model is a multi-product firm producing and selling two demandrelated products: $q_{1}$ and $q_{2}$. The multi-product firm purchases a material input in competitive markets. After converting the material input into different processed products, the multiproduct firm sells its final products in non-completive markets. The profit maximization's problem for the $j^{\text {th }}$ multi-product firm can be formulated as

$$
\operatorname{Max}_{q_{1}^{j}, q_{2}^{j}} \pi^{j}=\operatorname{Max}_{q_{1}^{j}, q_{2}^{j}}\left[\sum_{i=1}^{2}\left[\left(P_{i}\left(Q_{1}, Q_{2}\right)-k_{i} \times w\right) \times q_{i}^{j}-T P C_{i}\right]\right] .
$$

Where $P_{i}$ is the price of the $i^{\text {th }}$ final product; $Q_{1}$ and $Q_{2}$ are the industry's total quantities sold of product 1 and product 2, respectively; $k_{i}$ is the conversion factor associated with the $i^{\text {th }}$ final product; $1 T P C_{i}$ is the total cost of processing the material input into the $i^{\text {th }}$ final product; and

\footnotetext{
1 The conversion factor, $k_{i}$, refers to the amount of the material input needed to obtain one pound of the $i^{\text {th }}$ final product.
} 
$w$ is the price of the material input. Differentiation of Equation 1 with respect to $q_{1}^{j}$ and $q_{2}^{j}$ yields the following first-order conditions

(2)

$\frac{\partial \pi^{j}}{\partial q_{1}^{j}}=0==>P_{1}+q_{1}^{j} \frac{\partial P_{1}}{\partial Q_{1}} \frac{\partial Q_{1}}{\partial q_{1}^{j}}+q_{1}^{j} \frac{\partial P_{1}}{\partial Q_{2}} \frac{\partial Q_{2}}{\partial q_{1}^{j}}+q_{2}^{j} \frac{\partial P_{2}}{\partial Q_{1}} \frac{\partial Q_{1}}{\partial q_{1}^{j}}+q_{2}^{j} \frac{\partial P_{2}}{\partial Q_{2}} \frac{\partial Q_{2}}{\partial q_{1}^{j}}-k_{1} w-m p c_{1}=0$

(3)

$$
\frac{\partial \pi^{j}}{\partial q_{2}^{j}}=0=\Rightarrow P_{2}+q_{2}^{j} \frac{\partial P_{2}}{\partial Q_{2}} \frac{\partial Q_{2}}{\partial q_{2}^{j}}+q_{2}^{j} \frac{\partial P_{2}}{\partial Q_{1}} \frac{\partial Q_{1}}{\partial q_{2}^{j}}+q_{1}^{j} \frac{\partial P_{1}}{\partial Q_{2}} \frac{\partial Q_{2}}{\partial q_{2}^{j}}+q_{1}^{j} \frac{\partial P_{1}}{\partial Q_{1}} \frac{\partial Q_{1}}{\partial q_{2}^{j}}-k_{2} w-m p c_{2}=0
$$

Where $m p c_{1}$ and $m p c_{2}$ are the marginal processing costs of converting the material input into product 1 and product 2, respectively. Equations (2) and (3) can be expressed in terms of elasticities as

$$
\begin{aligned}
& P_{1}+P_{1} \eta_{11} \theta_{11}+P_{1} \eta_{12} \theta_{21}+P_{2}\left[\frac{q_{2}^{j}}{q_{1}^{j}}\right] \eta_{21} \theta_{11}+P_{2}\left[\frac{q_{2}^{j}}{q_{1}^{j}}\right] \eta_{22} \theta_{21}-k_{1} w-m p c_{1}=0 \\
& P_{2}+P_{2} \eta_{22} \theta_{22}+P_{2} \eta_{21} \theta_{12}+P_{1}\left[\frac{q_{1}^{j}}{q_{2}^{j}}\right] \eta_{12} \theta_{22}+P_{1}\left[\frac{q_{1}^{j}}{q_{2}^{j}}\right] \eta_{11} \theta_{12}-k_{2} w-m p c_{2}=0 .
\end{aligned}
$$

Where:

$\eta_{11}=\left[\frac{\partial P_{1}}{\partial Q_{1}} \frac{Q_{1}}{P_{1}}\right]:$ own price elasticity of the inverse demand for product 1 ;

$\theta_{11}=\left[\frac{\partial Q_{1}}{\partial q_{1}^{j}} \frac{q_{1}^{j}}{Q_{1}}\right]:$ own conjectural elasticity for product $1 ;$

$\eta_{12}=\left[\frac{\partial P_{1}}{\partial Q_{2}} \frac{Q_{2}}{P_{1}}\right]:$ cross price elasticity of the inverse demand for product 1 with respect to

product 2;

$\theta_{21}=\left[\frac{\partial Q_{2}}{\partial q_{1}^{j}} \frac{q_{1}^{j}}{Q_{2}}\right]:$ cross conjectural elasticity for product 2 with respect to product 1; 
$\eta_{21}=\left[\frac{\partial P_{2}}{\partial Q_{1}} \frac{Q_{1}}{P_{2}}\right]:$ cross price elasticity of the inverse demand for product 2 with respect to product 1;

$\eta_{22}=\left[\frac{\partial P_{2}}{\partial Q_{2}} \frac{Q_{2}}{P_{2}}\right]$ : own price elasticity of the inverse demand for product 2;

$\theta_{12}=\left[\frac{\partial Q_{1}}{\partial q_{2}^{j}} \frac{q_{2}^{j}}{Q_{1}}\right]:$ cross conjectural elasticity for product 1 with respect to product $2 ;$

$\theta_{22}=\left[\frac{\partial Q_{2}}{\partial q_{2}^{j}} \frac{q_{2}^{j}}{Q_{2}}\right]:$ own conjectural elasticity for product 2 .

In order to use aggregate data, multiply Equation (4) by $q_{1}^{j}$ and Equation (5) by $q_{2}^{j}$, assume constant conjectural variations and constant marginal processing costs, and sum over catfish processing plants yields

$$
P_{1} Q_{1}+P_{1} \eta_{11} \theta_{11} Q_{1}+P_{1} \eta_{12} \theta_{21} Q_{1}+P_{2} \eta_{21} \theta_{11} Q_{2}+P_{2} \eta_{22} \theta_{21} Q_{2}-k_{1} w Q_{1}-m p c_{1} Q_{1}=0
$$

$$
P_{2} Q_{2}+P_{2} \eta_{22} \theta_{22} Q_{2}+P_{2} \eta_{21} \theta_{12} Q_{2}+P_{1} \eta_{12} \theta_{22} Q_{1}+P_{1} \eta_{11} \theta_{12} Q_{1}-k_{2} w Q_{2}-m p c_{2} Q_{2}=0
$$

After a few algebraic manipulations, Equations (6) and (7) become

$$
\begin{aligned}
& M_{1}=-\left(\eta_{11} \theta_{11}+\eta_{12} \theta_{21}\right)-\left(\eta_{21} \theta_{11}+\eta_{22} \theta_{21}\right)\left[\frac{P_{2} Q_{2}}{P_{1} Q_{1}}\right]+\frac{m p c_{1}}{P_{1}} \\
& M_{2}=-\left(\eta_{22} \theta_{22}+\eta_{21} \theta_{12}\right)-\left(\eta_{12} \theta_{22}+\eta_{11} \theta_{12}\right)\left[\frac{P_{1} Q_{1}}{P_{2} Q_{2}}\right]+\frac{m p c_{2}}{P_{2}} .
\end{aligned}
$$

where $Q_{1}=\sum_{j=1}^{N} q_{1}^{j}$ and $Q_{2}=\sum_{j=1}^{N} q_{2}^{j}$ are the industry's total quantities sold of product 1 and product 2, respectively; $M_{1}=\left[\frac{P_{1}-k_{1} w}{P_{1}}\right]$ and $M_{2}=\left[\frac{P_{2}-k_{2} w}{P_{2}}\right]$ are the price margins for product 1 and product 2 , respectively.

\subsection{Empirical Application}

The theoretical model presented in the previous section is used to assess the degree of oligopoly power and cross-market effects in the US catfish processing industry. The US catfish 
processing industry is comprised of multi-product processing plants producing and selling various demand-related products. Each catfish processing plant purchases live catfish in competitive markets. After converting live catfish into processed catfish, the catfish processing plant sells its final products in non-completive markets. For simplicity and application purposes, we focus exclusively on fresh catfish fillet, denoted by $q_{1}$, and whole fresh catfish, denoted by $q_{2}$. The basis for our econometric model, therefore, is the margin equations (8) and (9). To estimate the parameters of the econometric model and following prior literature (e.g., Bouras and Engle, 2007; Bouras et al., 2017a), we assume that catfish processing plants use three inputs, namely, labor, capital and energy denoted respectively by $L, K$ and $E$. Assuming linear marginal processing costs, the econometric model in its final form is given by:

(10)

$$
M_{1}=-\left(\eta_{11} \theta_{11}+\eta_{12} \theta_{21}\right)-\left(\eta_{21} \theta_{11}+\eta_{22} \theta_{21}\right)\left[\frac{P_{2} Q_{2}}{P_{1} Q_{1}}\right]+\delta_{1}\left(\frac{P_{K}}{P_{1}}\right)+\delta_{2}\left(\frac{P_{E}}{P_{1}}\right)+\delta_{3}\left(\frac{P_{L}}{P_{1}}\right)+\varepsilon_{1}
$$

$$
M_{2}=-\left(\eta_{22} \theta_{22}+\eta_{21} \theta_{12}\right)-\left(\eta_{12} \theta_{22}+\eta_{11} \theta_{12}\right)\left[\frac{P_{1} Q_{1}}{P_{2} Q_{2}}\right]+\gamma_{1}\left(\frac{P_{K}}{P_{2}}\right)+\gamma_{2}\left(\frac{P_{E}}{P_{2}}\right)+\gamma_{3}\left(\frac{P_{L}}{P_{2}}\right)+\varepsilon_{2}
$$

Where $\delta$ 's and $\gamma$ 's are parameters to be estimated; $P_{K}, P_{E}$ and $P_{L}$ are the prices of capital, energy and labor, respectively; $\varepsilon_{1}$ and $\varepsilon_{2}$ are the error terms; and all the remaining variables and parameters are as previously defined. To overcome the identification problem, we use a two-step procedure. In the first step, we obtain the estimates for the own and cross price elasticities by estimating the inverse demand functions for fresh catfish fillet and whole fresh catfish. These estimates, in turn, are used in the second step to estimate the price margin equations. Towards this end, we estimate the following log-linear models

$$
\begin{aligned}
& \log \left(P_{1}\right)=\alpha_{0}+\eta_{11} \log \left(Q_{1}\right)+\eta_{12} \log \left(Q_{2}\right)+\alpha_{1} \log (t)+u_{1} \\
& \log \left(P_{2}\right)=\beta_{0}+\eta_{22} \log \left(Q_{2}\right)+\eta_{21} \log \left(Q_{1}\right)+\beta_{1} \log (t)+u_{2} .
\end{aligned}
$$

Where $P_{1}$ and $P_{2}$ are the prices of fresh catfish fillet and whole fresh catfish, respectively; $Q_{1}$ and $Q_{2}$ are the industry's total quantities sold of fresh catfish fillet and whole fresh catfish, respectively; and $t$ is a time trend variable.

\section{Data and Empirical Estimation}

\subsection{Data}

In order to evaluate the degree of market power and assess cross-market effects in the US catfish processing industry, we use monthly data ranging from $01 / 1991$ to $12 / 2012$. The data were compiled from a variety of sources. The bank prime loan rate, which is used as a proxy for the price of capital, was taken from the Federal Reserve of St. Louis; live catfish, whole fresh 
catfish and fresh catfish fillet prices, quantity sold of whole fresh catfish, and quantity sold of fresh catfish fillet were collected from the US Department of Agriculture. The price of electricity, which is used as a proxy for the price of energy, was collected from the US Department of Energy; and hourly minimum wage, which is used as a proxy for the price of labor, was obtained from the US Department of Labor. The descriptive statistical analysis is provided in Table 1.

Table 1: Descriptive Statistical Analysis

\begin{tabular}{|c|c|c|c|c|}
\hline Variable & Min & Max & Mean & $\begin{array}{l}\text { Standard } \\
\text { Deviation }\end{array}$ \\
\hline Bank Prime Loan Rate (\%) & 3.3 & 9.5 & 6.3 & 2.1 \\
\hline Price of live catfish $(\$ / L b)$ & 0.5 & 1.3 & 0.8 & 0.1 \\
\hline Price of whole fresh catfish $(\$ / L b)$ & 1.2 & 2.7 & 1.6 & 0.2 \\
\hline Quantity sold of whole fresh catfish (1,000 Lbs) & 1484.0 & 4928.0 & 3136.2 & 587.0 \\
\hline Price of fresh catfish fillet (\$/Lb) & 2.4 & 4.9 & 3.0 & 0.5 \\
\hline Quantity sold of fresh catfish fillet (1,000 Lbs) & 1877.0 & 6815.0 & 4050.9 & 1073.0 \\
\hline Electricity price (e/kilowatt hour) & 4.2 & 7.7 & 5.4 & 0.9 \\
\hline Hourly minimum wage (\$/Hour) & 3.8 & 7.3 & 5.3 & 1.0 \\
\hline
\end{tabular}

\subsection{Empirical Estimation}

The empirical assessment of the degree of market power and market-cross effects is carried out using a two-step procedure. In the first step, we estimate the inverse demand functions for fresh catfish fillet and whole fresh catfish. Table 2 contains own and cross price elasticities of the inverse demand along with other log-linear models' parameter estimates.

Table 2: Parameter Estimates for the inverse demand for fresh catfish fillet and whole fresh catfish.

\begin{tabular}{lll}
\hline Parameter & Estimate & Standard Error \\
\hline Fresh Catfish Fillet & & 0.564 \\
\hline$\alpha_{0}$ & $4.709^{*}$ & 0.052 \\
$\eta_{11}$ & $-0.314^{*}$ & 0.080 \\
$\eta_{12}$ & $-0.173^{* *}$ & 0.019 \\
$\alpha_{1}$ & $0.077^{*}$ & \\
$\mathrm{R}^{2}$ & $79.41 \%$ & \\
Log-Likelihood & 336.14 & \\
Akaike Info Criterion & -2.52 & \\
F-Statistic & $334.19^{*}$ & 0.596 \\
\hline Whole Fresh Catfish & & 0.079 \\
\hline$\beta_{0}$ & $4.151^{*}$ & 0.058 \\
$\eta_{22}$ & $-0.280^{*}$ & 0.014 \\
$\eta_{21}$ & $-0.191^{*}$ &
\end{tabular}




$\begin{array}{ll}\mathrm{R}^{2} & 59.42 \% \\ \text { Log-Likelihood } & 268.51 \\ \text { Akaike Info Criterion } & -2.00 \\ \text { F-Statistic } & 126.90^{*}\end{array}$

Note: ${ }^{*}$ and ${ }^{* *}$ represent $1 \%$, and 5\% significance level, respectively.

Having obtained the estimates for own and cross-price elasticities of the inverse demand functions, these estimates are used in the second step to estimate the margin equations for fresh catfish fillet and whole fresh catfish. The margin equations are estimated jointly using Three-Stage Least Squares method (3SLS) with correction for autocorrelation and heteroscedasticity using Newey and West's approach (1987). Table 3 provides parameter estimates for the margin equations for both fresh catfish fillet and whole fresh catfish.

Table 3: Parameter Estimates of the Margin Equations for fresh catfish fillet and Whole Fresh Catfish

\begin{tabular}{lcc}
\hline Parameter & Estimate & Standard Error \\
\hline Fresh Catfish Fillet & 0.315 & 0.270 \\
\hline$\theta_{11}$ & 0.204 & 0.277 \\
$\theta_{21}$ & $-0.007^{* *}$ & 0.004 \\
$\delta_{1}$ & -0.004 & 0.019 \\
$\delta_{2}$ & $0.143^{*}$ & 0.025 \\
$\delta_{3}$ & & \\
\hline Whole Fresh Catfish & $0.338^{* * *}$ & 0.182 \\
\hline$\theta_{22}$ & -0.105 & 0.108 \\
$\theta_{12}$ & $0.024^{*}$ & 0.003 \\
$\gamma_{1}$ & -0.022 & 0.014 \\
$\gamma_{2}$ & $0.031^{* * *}$ & 0.017 \\
$\gamma_{3}$ & &
\end{tabular}

Note: ${ }^{* * *}$, and ${ }^{* * *}$ represent $1 \%, 5 \%$, and $10 \%$ significance level, respectively.

Of particular relevance are the own and cross conjectural elasticities: $\theta_{11}, \theta_{22}, \theta_{12}$ and $\theta_{21}$. These parameters are used to test statistically the hypotheses of market power and crossmarket effects. These statistical tests are summarized in Table 4. The first hypothesis is the inexistence of cross market effects. This test amounts to testing whether $\theta_{12}$ and $\theta_{21}$ are jointly equal to zero. With a Chi-square statistic of 1.66 , the hypothesis of no cross-market effects cannot be rejected. The second hypothesis is the inexistence of market power. This test is equivalent to testing whether $\theta_{11}, \theta_{22}, \theta_{12}$ and $\theta_{21}$ are jointly equal to zero. With a Chi- 
square statistic of 206.34, the hypothesis of the inexistence of marker power can be rejected at the $1 \%$ significance level.

Table 4: Chi-squared Statistical Tests

Null Hypothesis

No Cross Effects:

$$
H_{0}: \theta_{12}=\theta_{21}=0
$$

No Market Power:

$$
H_{0}: \theta_{11}=\theta_{22}=\theta_{12}=\theta_{21}=0
$$

Note: ${ }^{*}$ represents $1 \%$ significance level.

\section{Lerner Indices}

To further analyze the degree of market power in the US catfish processing industry we compute the Lerner indices, commonly known as the oligopoly power indices, at the industry level for both fresh catfish fillet and whole fresh catfish. Using Equations (8) and (9), the Lerner indices at the industry level for both fresh fillet and whole fresh catfish .are, respectively, given by

$$
\begin{aligned}
& L_{1}=\left(-\left(\eta_{11} \theta_{11}+\eta_{12} \theta_{21}\right)-\left(\eta_{21} \theta_{11}+\eta_{22} \theta_{21}\right)\left[\frac{P_{2} Q_{2}}{P_{1} Q_{1}}\right]\right) \\
& L_{2}=\left(-\left(\eta_{22} \theta_{22}+\eta_{21} \theta_{12}\right)-\left(\eta_{12} \theta_{22}+\eta_{11} \theta_{12}\right)\left[\frac{P_{1} Q_{1}}{P_{2} Q_{2}}\right]\right) .
\end{aligned}
$$

The estimates of the Lerner indices at the industry level for both fresh catfish fillet and whole fresh catfish for various years are reported in Table 5 and Figure 1 . According to the results, the Lerner index for fresh catfish fillet ranges from nearly $17 \%$ to nearly $21 \%$ while that for whole fresh catfish ranges from over $11 \%$ to over $15 \%$. Evaluated at the mean values of the variables, the estimates of the Lerner indices for fresh catfish fillet and whole fresh catfish are $18.2 \%$ and $13.3 \%$, respectively. These estimates are statistically significant at the $1 \%$ level. As shown in Table 5, the Lerner index for fresh catfish fillet is higher than that for whole fresh catfish, implying that the price distortion is more pronounced in the market for fresh catfish fillet than it is in the market for whole fresh catfish. Although prior literature regarding the estimation of the oligopoly power index in the US catfish processing industry is scant, using aggregate data from 1977 to 1993, Kouka (1995) reported an average oligopoly power index of $44 \%$. 
Table 5: Lerner Indices for Fresh Catfish Fillet and Whole Fresh Catfish for Selected Years

\begin{tabular}{lll}
\hline & Lerner Index & \\
\cline { 2 - 3 } Year & Fresh Catfish Fillet & Whole Fresh Catfish \\
\hline 1992 & 0.2088 & 0.1125 \\
1994 & 0.2035 & 0.1154 \\
1996 & 0.1935 & 0.1221 \\
1998 & 0.1843 & 0.1304 \\
2000 & 0.1799 & 0.1354 \\
2002 & 0.1725 & 0.1466 \\
2004 & 0.1695 & 0.1528 \\
2006 & 0.1722 & 0.1474 \\
2008 & 0.1746 & 0.1434 \\
2010 & 0.1772 & 0.1393 \\
2012 & 0.1910 & 0.1242 \\
Average & $\mathbf{0 . 1 8 2 0 ^ { * }}$ & $\mathbf{0 . 1 3 3 0 ^ { * }}$ \\
\hline
\end{tabular}

Note: * represents $1 \%$ significance level.

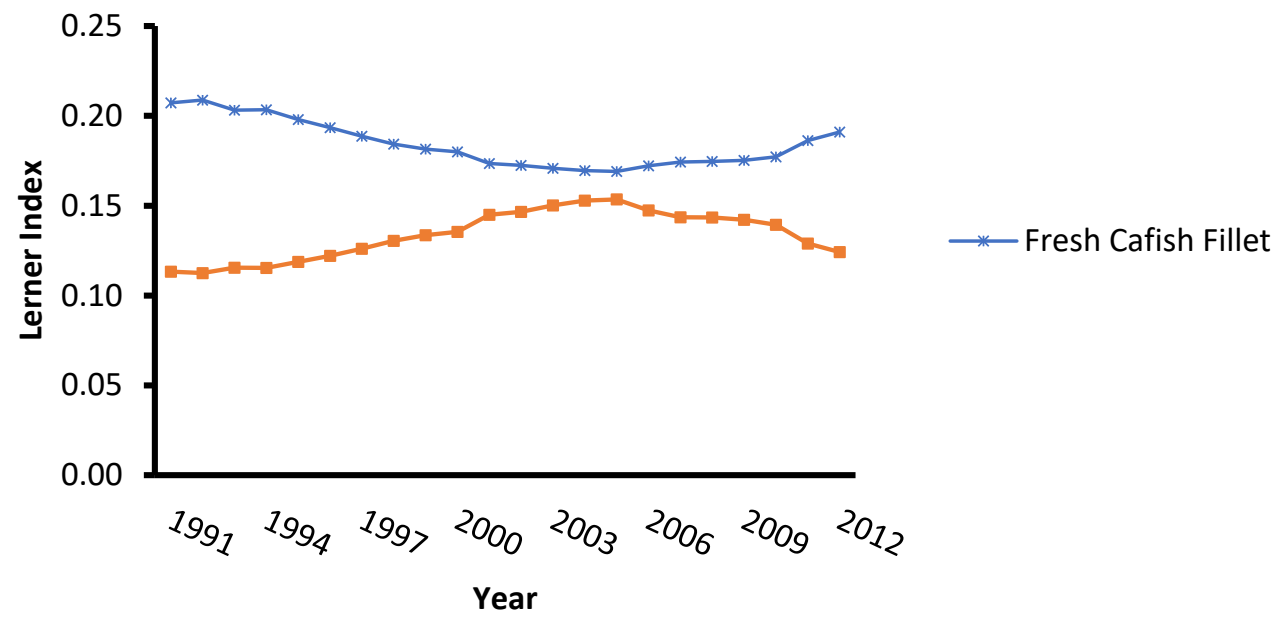

Figure 1: Yearly Lerner Indices for Fresh Catfish Fillet and Whole Fresh Catfish.

\section{Concluding Remarks}

The objective of this paper is to empirically evaluate the degree of market power and assess cross-market effects in the US catfish processing industry. To this end, the paper uses and estimates a conjectural variation model that takes into account both the oligopoly power and cross-market effects. Using monthly data from the US catfish processing industry while focusing exclusively on the market for whole fresh catfish and fresh catfish fillet, Chi-square statistical tests show that while the hypothesis of cross-market effects can be rejected, the existence of some degree of market power cannot be ruled out. In addition, the estimates of the oligopoly power index for fresh catfish fillet is higher than that for whole fresh catfish, 
implying that the price distortion is more pronounced in the market for fresh catfish fillet than it is in the market for whole fresh catfish.

\section{References}

[1] Appelbaum, E. (1982). "The estimation of the degree of oligopoly power." Journal of Econometrics 19:2/3, 287-299.

[2] Houck, J. P. (1985). "The link between supply response and production elasticities." Central Journal of Agricultural Economics 7:1, 11-17.

[3] Kinnucan, H., and G. Sullivan (1986). "Monopsonistic food processing and farm prices: The case of the West Alabama catfish industry." Journal of Agricultural and Applied Economics 18:2, 15-24.

[4] Bouras D., and C. Engle (2007). "Assessing oligopoly and oligopsony power in the U.S. catfish industry." Agribusiness Journal 25:1, 47-57.

[5] Bouras, D. Kaliba, A., Bouras, A., and A. Dutta (2010). "Testing for market power in the U.S. catfish industry: A dynamic error correction approach." Journal of Applied Economics and Policy 29: (Spring), 15-33.

[6] Bouras, D., Anunoby, O., and O. Saitakhunov (2017a). "Output price risk, material input price risk, and price margins: Evidence from the US catfish industry." Journal of Economics \& Management 29: 23-36.

[7] Bouras, D., Frank, T., and E. Burgess (2017b). "Functional forms and oligopolistic models: An empirical analysis." International Journal of Economics and Financial Issues 7: 4, 1-5.

[8] Dillard, J. G. (1995). Organization of the catfish industry: Market structureconduct-performance Catfish Farmers of America, Annual Meetings, Memphis, Tennessee.

[9] Federal Reserve Bank of St. Louis, (1992-2012). Economic Data: Bank Prime Loan Rate.

[10] Gelfand, M. D. and P.T. Spiller (1987). "Entry barriers and multiproduct oligopolies: do they forbear or spoil?" International Journal of Industrial Organization 5:1, 101-113.

[11] Kouka, P. (1995). "An empirical model of pricing in the catfish industry." Marine Resource Economics 10:2, 161-169.

[12] Newey, W., and K. West (1987). "A simple, positive semi-definite, heteroscedastic and autocorrelation consistent covariance matrix." Econometric 55:3, 703-708.

[13] Schroeter, J., and A. Azzam (1991) "Measuring market power in multi-product oligopolies: the US meat industry." Applied Economics 22:10, 1365-1376

[14] U.S. Department of Agriculture. (1992-2012). Catfish and trout production. National Agricultural Statistics Service.

[15] U.S. Department of Energy, (1992-2012). Energy information administration. Monthly Energy Review.

[16] U.S. Department of Labor, (1992-2012). Bureau of labor statistics, employment and earnings. 